\title{
Users of antiasthma drugs in Iceland: a drug utilization study
}

\author{
T. Gislason*, Ó. Ólafsson**, A. Sigvaldason*
}

Users of antiasthma drugs in Iceland: a drug utilization study. T. Gislason, Ó. Ólafsson, A. Sigvaldason. (CERS Journals Ltd 1997.

ABSTRACT: There has been an increasing consensus worldwide on how to treat asthma, and, simultaneously, an increase in the sales of antiasthma drugs. However, little is known about actual drug use, dosage, combinations of drugs, etc., or about the clinical characteristics of patients using these drugs.

All individuals with prescriptions for antiasthma drugs, who came to Icelandic pharmacies during March 1994, were invited to participate. By means of questionnaires, the pharmacists recorded the age and gender of the patient, the speciality of the prescribing doctor, as well as the name of the drug, total amount prescribed, and dosage. The patients were asked to answer another questionnaire on their clinical diagnosis, usage of other antiasthma drugs, etc.

The pharmacists registered 2,026 individuals, with 2,687 prescriptions: 1,574 for beta ${ }_{2}$-agonists, 838 for inhaled corticosteroids, 208 for theophylline, 48 for anticholinergic drugs, and 19 for cromoglycates. One thousand, three hundred and fifty one patients answered the questionnaires. The majority $(67 \%)$ claimed to have asthma, 18\% chronic bronchitis, $11 \%$ emphysema and $5 \%$ other diseases or symp-

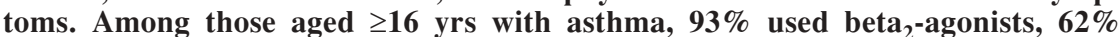
inhaled corticosteroids, $19 \%$ theophylline, and very few used other drugs. The most commonly used combination $(57 \%)$ was beta ${ }_{2}$-agonists with inhaled corticosteroids. Thirty one per cent used beta ${ }_{2}$-agonists as monotherapy, and $5 \%$ used only inhaled corticosteroids. Theophylline was used mainly in combination with beta ${ }_{2}$-agonists and inhaled corticosteroids.

In conclusion, our data suggest that two thirds of antiasthma drug users have asthma and that most are treated according to present guidelines. The use of inhaled corticosteroids, however, seems somewhat less than optimal.

Eur Respir J 1997; 10: 1230-1234.

During the last few years, there has been increasing consensus worldwide on how to treat asthma, and therapeutic guidelines have been published in many countries $[1,2]$. The mildest cases are treated only with beta $_{2}$-agonists, but inhaled corticosteroids play the chief role for more severe cases. The emphasis on the use of inhaled corticosteroids is in accordance with the view that asthma is a chronic inflammatory disorder and that the contraction of bronchial musculature is secondary.

The use of antiasthma drugs increased more than threefold in the Nordic countries from 1979 to 1989 [3], and a similar trend has been reported elsewhere, e.g. in the USA and New Zealand [4]. This increase in use of antiasthma drugs coincides with changed therapeutic traditions in asthma, an increase in the prevalence (awareness) of asthma, and possibly also with new indications for antiasthma drugs in other pulmonary disorders.

Apart from increasing sales figures for antiasthma drugs, there is limited epidemiological information about their use. The aim of this study was to answer the following questions about antiasthma drugs in an epidemiologically well-defined population: 1) Who is the user (age and gender)? 2) How are the drugs prescribed (amount and dosage)? 3) Who does the prescribing? 4) Who initiated the treatment? 5) Have the patients been
*Vífilsstadir, Pulmonary Dept, Gardabær, Iceland. **DELTA Ltd, Hafnarfjordur, Iceland.

Correspondence: T. Gislason

Vífilsstadir

Pulmonary Dept

210 Gardabær

Iceland

Keywords: Asthma

beta $_{2}$-agonists

chronic bronchitis

corticosteroids

epidemiology

theophylline

Received: December 191995

Accepted after revision October 231996

The Icelandic University Hospital Research Fund and Oddur Olafsson Memorial Fund supported this study financially. taught how to use inhaled drug devices? 6) What are the clinical symptoms? 7) What is the clinical diagnosis? 8) In which combinations are the antiasthma drugs used? and 9) Is their usage in accordance with guidelines?

\section{Material and methods}

\section{Background information}

The total population of Iceland on December 31, 1993 , was 265,064 . There were 43 Icelandic pharmacies. Antiasthma drugs are only sold on prescription. They are subsidized by the state social security system and the patients only pay US\$ 8-20 for a 3 month supply of each drug. In November 1993, a pilot study was carried out in two pharmacies. Based on that experience, two types of questionnaire were constructed, one for the pharmacist and another for the patient (these questionnaires are available in an English translation from the corresponding author). The survey was then introduced to all pharmacists, followed by a letter of recommendation by the Association of Pharmacists and also by the Ministry of Health, with the understanding that no personal data would be collected. 
Table 1. - Defined daily doses (DDD) of commonly used antiasthma drugs

\begin{tabular}{ll}
\hline Drug & \multicolumn{1}{c}{ One DDD } \\
\hline Beta 2 -agonists & $0.8 \mathrm{mg}$ inhaled aerosol/powder \\
Salbutamol & $12 \mathrm{mg}$ oral/parenteral \\
& $2 \mathrm{mg} \mathrm{inhaled} \mathrm{aerosol/powder}$ \\
Terbutaline & $15 \mathrm{mg}$ oral/parenteral \\
& $0.1 \mathrm{mg}$ inhaled aerosol/powder \\
Salmeterol & $20 \mathrm{mg}$ oral \\
Bambuterol & \\
Inhaled steroids & $0.8 \mathrm{mg}$ inhaled aerosol/powder \\
Beclomethasone & $0.8 \mathrm{mg}$ inhaled aerosol/powder \\
Budesonide & \\
Anticholinergics & $0.12 \mathrm{mg}$ inhaled aerosol/powder \\
Ipratropium & $0.6 \mathrm{mg}$ inhaled aerosol \\
Oxitropium & $40 \mathrm{mg}$ inhaled aerosol/powder \\
Cromoglycate & $400 \mathrm{mg}$ oral \\
Theophylline &
\end{tabular}

\section{Procedure}

Our aim was to register all prescriptions for drugs in group R O3 of the Anatomical Therapeutic Chemical (ATC) classification that were sold by Icelandic pharmacies during March 1994 [5]. Table 1 shows the defined daily doses (DDD) for the most commonly used drugs in group $\mathrm{R} \mathrm{O} 3$. The registration of drug use was based on two types of questionnaire: one answered by the pharmacists; and one that all patients were asked to answer.

Pharmacists' questionnaire. The pharmacist was asked to complete a special questionnaire on all occasions when a prescription for an antiasthma drug was presented at the pharmacy. The prescription was either brought to the pharmacy (by the patient or a relative) or was phoned in by the doctor. The pharmacist was asked to record the patient's gender and year of birth, the name of the drug, form of preparation, concentration, total amount prescribed and dosage, and the prescribing physician's speciality.

Patients' questionnaire. The pharmacist asked the patient to complete a questionnaire marked with the same number as the one the pharmacist had filled in. The patient was given the choice of answering the questionnaire at once or later, in which case he or she posted it in a prepaid envelope. As no personal data were recorded, it was not possible to remind nonresponders to send in the questionnaire. Parents were asked to answer for their young children. The patients were asked about: 1) the speciality of the doctor who initially prescribed the drug; 2) the diagnosis; 3) whether the use of inhaled drugs had been taught, and, if so, by whom; 4) the use of other antiasthma drugs; 5) respiratory symptoms (these questions were those used in the European Community Respiratory Health survey [6]); and 6) smoking habits.

\section{Statistical analysis}

Mean values and one standard deviation $( \pm S D)$ were used for continuous variables and a two-sided t-test for comparison. A chi-squared test was used for comparison of groups. A p-value of less than 0.05 was considered significant.

\section{Results}

In March 1994, the pharmacists reported a total of 2,687 prescriptions for antiasthma drugs at Icelandic pharmacies, from 2,026 individuals. The majority of the prescriptions $(66 \%)$ came from pharmacies in the capital city, Reykjavík, and surrounding suburbs. All pharmacies participated except one, but we were later allowed to go through their sales records for antiasthma drugs in March and fill in the pharmacists' questionnaires.

Altogether, 404 (20\%) individuals had their prescriptions phoned in by their doctors. In 440 cases, the drug(s) were collected from the pharmacy by someone other than the patient, and this person was asked to deliver the questionnaire to the patient. There were 476 mailed questionnaires that were received later. Altogether, there were 1,351 completed questionnaires from the patients, a response rate of $67 \%$. Forty two individuals refused to participate. The participation among the 1,351 patients was similar in all age groups, and no gender difference was found compared to the 2,026 reported by the pharmacists.

\section{Age and gender}

Among the users, there were 1,046 (52\%) females and $957(48 \%)$ males (fig. 1). Information about gender or age was lacking for 30 individuals. Altogether, 19\% were under the age of $5 \mathrm{yrs}$, and $28 \%$ were $65 \mathrm{yrs}$ of age or older. Boys were overrepresented among the youngest $(<5$ yrs) antiasthma drug users (fig. 1) $(\mathrm{p}<0.001)$. In those aged 5-45 yrs, the number of males and females was similar, but at older ages there were more females than males $(\mathrm{p}<0.001)$.

The antiasthma drug users aged <5 yrs in March 1994 amounted to $1.8 \%$ of the total Icelandic population for that age group (fig. 2). In the next four 10 yr age groups, the users amounted to a relatively low percentage of the total population $(\sim 0.4 \%)$, but after 50 yrs of age there was an increase. Among those aged $\geq 65$ yrs, $2 \%$ of the total population had an antiasthma prescription filled during March 1994.

Prescriptions for drugs used for chronic disorders in Iceland are usually for a 3 month supply (table 2), except for children. If we assume that the sale of antiasthma drugs in March 1994 was one third of the total

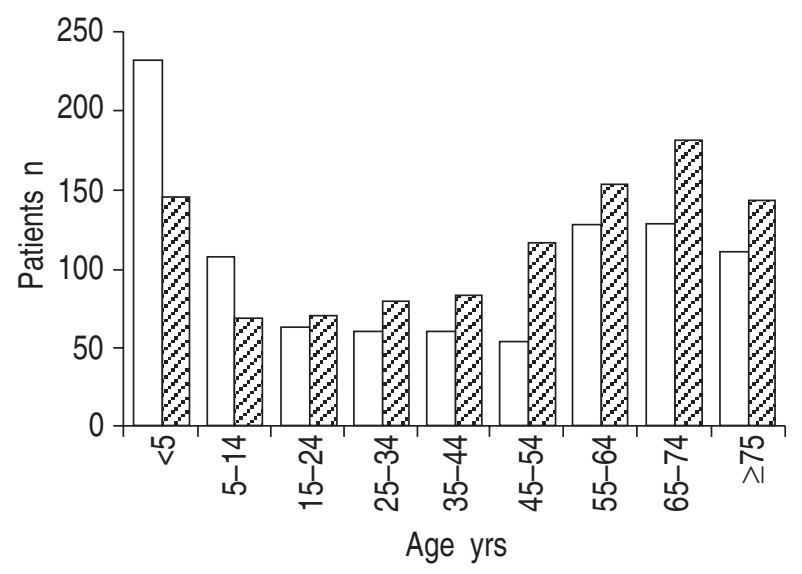

Fig. 1. - Number of males ( $\square$ ) and females ( $\square$ ) in each age group using antiasthma medication in March 1994. 
use during that month, then: at each time, 2,026 individuals $\times 3 \times 100 / 265,064$, i.e. $2.3 \%$, of the Icelandic population was using antiasthma drugs (fig. 2). Among those aged $\geq 65$ yrs, approximately $6 \%$ of the population was using antiasthma drugs, compared with only about $1 \%$ of those aged 5-44 yrs.

\section{Amount and dosage}

There were, in total, 1,574 prescriptions for selective

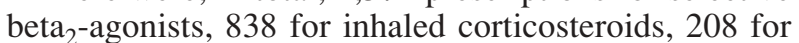
theophylline, 48 for anticholinergics, and 19 for cromoglycate (table 2). On average, there were 83 DDDs for each prescription. The total use of antiasthma drugs measured as DDD per 1,000 inhabitants was 2,687 (prescriptions $) \times 83($ DDD $) \times 12$ (months $) \times 1000 /(265,064$ $($ total population $) \times 365$ (days) $)=27.7$ DDD per 1,000 . The amount of cromoglycate prescribed was, proportionately, the lowest (table 2). The mean prescription for beta $_{2}$-agonists was for 73 DDD. The amount of beta $a_{2}$-agonists was lowest $(\mathrm{p}<0.0001)$ for those 38 individuals who obtained a mixture (22 DDD), but, for those 42 who were given beta ${ }_{2}$-agonists as tablets, was similar to that of the vast majority $(n=1,471)$ who obtained inhaled drugs. The theophylline and anticholinergics were usually to be used for 120 days (table 2).

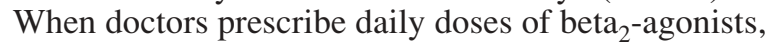
they often prescribe flexible doses. The use of inhaled corticosteroids, on the other hand, is more stable, and their mean $( \pm \mathrm{SD})$ daily dose was $1,053( \pm 616) \mu \mathrm{g} \cdot$ day $^{-1}$. Individual daily doses vary a great deal. The largest group (50\%) took 800-1,200 $\mu \mathrm{g} \cdot \mathrm{day}^{-1}, 6 \%$ took $<400$ $\mu \mathrm{g} \cdot \mathrm{day}^{-1}$, and $9 \%$ took $\geq 2,000 \mu \mathrm{g} \cdot \mathrm{day}^{-1}$. The mean $( \pm \mathrm{SD})$ daily dose for children aged $<5$ yrs $(n=150)$ was 1,538 $( \pm 972) \mu \mathrm{g} \cdot \mathrm{day}^{-1}$. Those aged 5-15 yrs had the lowest daily dose, $701( \pm 359) \mu \mathrm{g} \cdot \mathrm{day}^{-1}$. Among the 70 individuals with a daily dose of $\geq 2,000 \mu \mathrm{g} \cdot \mathrm{day}^{-1}$, 49 were aged $\leq 5$ yrs.

\section{Who is prescribing?}

On 1,916 occasions, the speciality of the prescribing doctor was recorded. Altogether, 1,302 (68\%) of the prescriptions came from general practitioners, $313(16 \%)$ from pulmonary doctors and allergists, $122(6 \%)$ from paediatricians, and 179 (9\%) from other doctors.

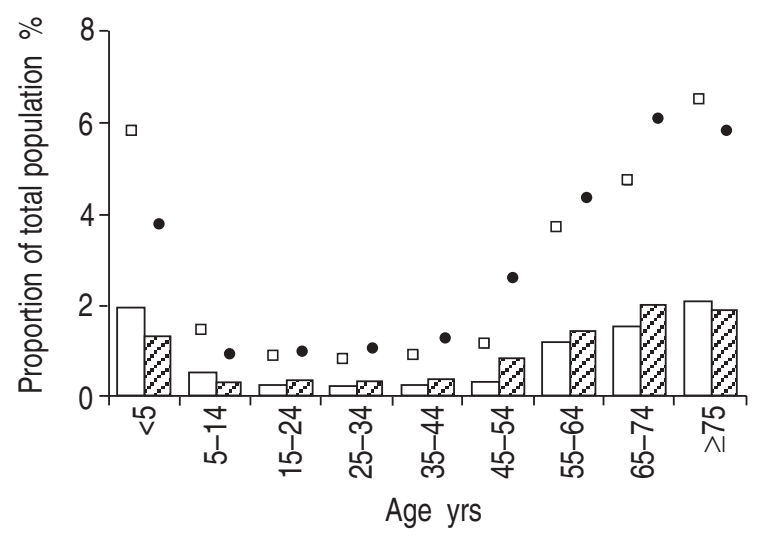

Fig. 2. - Proportion of total population ( $\square$ : males, and $\square$ : females) in Iceland obtaining antiasthma medication in March 1994. Estimate of the total use of antiasthma drugs in Iceland ( $\square$ : males and $\bullet$ females) based on the assumption that one third of the users visited the pharmacies during 1 month.
Table 2. - Categories of antiasthma drugs, number of prescriptions, number of defined daily doses (DDDs), mean number of DDDs per 1,000 inhabitants based on our data for March 1994, and the official 1994 sales figures

\begin{tabular}{lcccc}
\hline $\begin{array}{l}\text { Drug } \\
\text { category }\end{array}$ & Pres & $\begin{array}{c}\text { DDD } \\
\text { per pres } \\
\mathrm{n}\end{array}$ & $\begin{array}{c}\text { DDD } \\
\text { per } 1,000^{\$} \\
\mathrm{n}\end{array}$ & $\begin{array}{c}\text { DDD sales } \\
\text { per 1,000 } \\
\mathrm{n}\end{array}$ \\
\hline Beta 2-agonists & 1574 & $\begin{array}{c}73 \\
(70-75)\end{array}$ & $\begin{array}{c}14.3 \\
(52)\end{array}$ & 19.4 \\
Inhaled steroids & 838 & $\begin{array}{c}94 \\
(90-99)\end{array}$ & $\begin{array}{c}(3.8 \\
(35)\end{array}$ & 13.9 \\
Anticholinergics & 48 & $\begin{array}{c}120 \\
(100-139)\end{array}$ & $\begin{array}{c}0.7 \\
(2.4)\end{array}$ & 2.0 \\
Cromoglycate & 19 & $\begin{array}{c}20 \\
(14-16)\end{array}$ & $\begin{array}{c}0.05 \\
(0.2)\end{array}$ & 0.1 \\
Theophylline & 208 & $\begin{array}{c}114 \\
(109-119)\end{array}$ & $\begin{array}{c}2.9 \\
(1)\end{array}$ & 4.7 \\
\hline Total & 2687 & $83(81-85)$ & 27.7 & 40.1 \\
\hline
\end{tabular}

Pres: prescription; per 1,000: per 1,000 inhabitants; $\$$ mean, and $95 \%$ confidence interval in parenthesis; $\$$ : mean, and percentage in parenthesis.

\section{Speciality of doctor initiating treatment}

In 1,080 cases, there was information about who had started treatment with beta $_{2}$-adrenergic drugs. General practitioners initiated this type of treatment on 485 occasions (45\%), pulmonary/allergists on 423 occasions (39\%), paediatricians on 118 occasions $(11 \%)$, and others on 54 occasions (5\%). In 584 cases, there was information about the doctor who initiated treatment with inhaled corticosteroids. General practitioners had started this treatment in 225 cases $(38 \%)$, pulmonary doctors/allergists in $267(46 \%)$, paediatricians in $71(12 \%)$, and others in 21 cases (4\%). Among the 131 individuals with theophylline, pulmonary/allergists had initiated this treatment in $69 \%$ of the cases.

Has someone taught you how to use inhaled drug devices?

Among the 1,351 individuals answering this question, $1,286(95 \%)$ had been taught how to use the device. Doctors had taught the majority $(84 \%)$.

\section{Clinical diagnosis}

In total, 1,351 individuals reported why they were being treated (table 3 ). The majority claimed that they suffered from asthma (67\%). Approximately the same number of males and females were being treated for asthma, but there were proportionally more females with chronic bronchitis (table 3). Individuals with emphysema were oldest ( $65 \pm 17 \mathrm{yrs})$, and those with poorly defined diagnosis (cough, common cold or don't know) were youngest. There was no difference in the proportion of prescriptions from general practitioners and other specialists in relation to clinical diagnosis.

\section{Clinical symptoms}

Two thirds of the antiasthma drug users reported wheezing or whistling during the preceding 12 months; these symptoms were often accompanied by dyspnoea and occurred without having a cold (table 4). Those treated with theophylline most often reported asthma attacks and treatment with oral corticosteroids, most often during the preceding 12 months (table 4 ). 
Table 3. - Indications for drug prescription: number, gender and mean age

\begin{tabular}{lcccc}
\hline & & \multicolumn{2}{c}{ Gender } & \\
\cline { 3 - 5 } & Prescription & Male & Female & Age \\
& $\mathrm{n}(\%)$ & $\mathrm{n}(\%)$ & $445(\%)$ & yrs \\
\hline Asthma & $904(67)$ & $443(70)$ & $98(64)$ & $38( \pm 28)$ \\
Chronic bronchitis & $241(18)$ & $98(15)$ & $139(20)$ & $40( \pm 27)$ \\
Emphysema & $144(11)$ & $74(12)$ & $69(10)$ & $65( \pm 17)$ \\
Cough & $23(2)$ & $9(1)$ & $14(2)$ & $25( \pm 26)$ \\
Common cold & $19(1)$ & $5(1)$ & $13(2)$ & $19( \pm 24)$ \\
Don't know & $20(1)$ & $8(1)$ & $12(2)$ & $32( \pm 24)$ \\
\hline Total & 1351 & 637 & 692 & $41( \pm 28)$ \\
\hline \multirow{5}{*}{ meant } & & & &
\end{tabular}

Table 4. - Respiratory symptoms during the last 12 months (in individuals aged $\geq 16$ yrs) among those treated with different antiasthma drugs

\begin{tabular}{lccc}
\hline & $\begin{array}{c}\text { Beta }_{2}{ }^{-} \\
\text {agonists } \\
(\mathrm{n}=830)\end{array}$ & $\begin{array}{c}\text { Inhaled } \\
\text { steroids } \\
(\mathrm{n}=584)\end{array}$ & $\begin{array}{c}\text { Theo- } \\
\text { phylline } \\
(\mathrm{n}=190)\end{array}$ \\
\hline $\begin{array}{l}\text { Wheezing or whistling \% } \\
\text { If yes: }\end{array}$ & 66 & 68 & 65 \\
Dyspnoea while wheezing \% & 85 & 86 & 85 \\
Wheezing without a cold \% & 73 & 75 & 76 \\
Awakened by dyspnoea \% & 34 & 34 & 40 \\
Awakened by cough \% & 52 & 54 & 48 \\
Asthma attack ever \% & 47 & 47 & 51 \\
Received prednisolone & 38 & 43 & 53 \\
tablets \% & & & \\
\end{tabular}

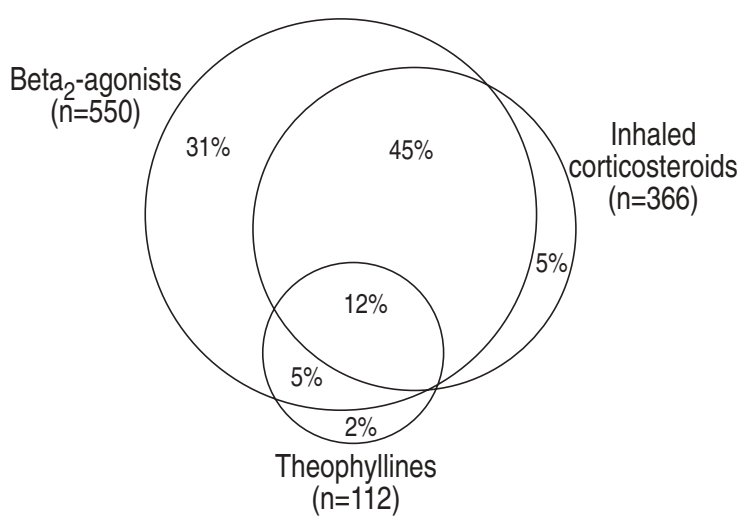

Fig. 3. - Combinations of antiasthma medication for those with diagnosis of asthma (in individuals aged $\geq 16 \mathrm{yrs}$ ).

\section{Smoking habits}

Among those aged $\geq 16$ yrs, $24 \%$ were daily smokers, $5 \%$ occasional smokers, $34 \%$ had never smoked, and $37 \%$ had quit, on average, 11 yrs previously. Among those with chronic bronchitis, $37 \%$ were current smokers, compared with $29 \%$ of those with emphysema, and $20 \%$ of the asthmatics. Among the emphysema patients, $59 \%$ had quit smoking.

\section{Asthma treatment}

There were, altogether, 591 individuals aged $\geq 16$ yrs who were treated because of asthma, of whom $93 \%$ were receiving selective beta-agonists, $62 \%$ inhaled corticosteroids, and $19 \%$ theophylline (fig. 3). Very few patients used anticholinergics $(2.9 \%)$ or cromoglycate $(1.2 \%)$.

In total, $31 \%$ of the asthmatics had beta ${ }_{2}$-agonists as monotherapy and $5 \%$ had inhaled corticosteroids as monotherapy (fig. 3). The largest group (57\%) was treated with a combination of beta 2 -agonists and inhaled corticosteroids, and one fifth of this group also used theophylline. The use of theophylline is, thus, mainly as a third drug, and its use as monotherapy is limited (2\%).

Among those 209 asthma patients who had received oral cortisone during the preceding 12 months, $73 \%$ had used some kind of inhaled corticosteroids and 57 (27\%) had not.

\section{Discussion}

There were, in total, 2,687 prescriptions for antiasthma drugs recorded at all Icelandic pharmacies during March 1994. This was about $70 \%$ of the mean monthly total sales of antiasthma drugs in 1994. A part of the total sales was at hospitals and clinics that were not involved in this study. It is also possible that not all antiasthma drug prescriptions were registered in this survey. Any part not found, however, could only be small, and there was no systematic bias, as the proportion of different antiasthma drugs registered was the same as the total annual use (table 2). Therefore, we estimate that the present data reflect the use of antiasthma drugs at the time the survey was performed. The proportion of prescriptions from general practitioners and specialists was similar to the results of a previous study on the use of antiulcer drugs carried out in Iceland in April 1991 [7]. The response rate for the patients' questionnaires was higher in the present study, probably because, at the time of purchase, the option to post replies was available.

Quite often, prescriptions for antiasthma drugs came from general practitioners (68\%) and "only" $23 \%$ from specialists, including paediatricians. On the other hand, the proportions for those who initiated the treatment are different. Thus, treatment with beta ${ }_{2}$-agonists was started in $50 \%$ of cases by specialists, and inhaled steroids in $58 \%$ of cases. Therefore, it seems that respiratory disorders are commonly diagnosed by specialists, who initiate treatment, but therapy is continued by general practitioners.

The correct use of inhaled drugs is very important, as they are often incorrectly used [8] and are, therefore, not as effective as expected. Most Icelandic patients have been taught how to administer the drug prescribed, but this survey does not, of course, reveal their actual status.

The reliability of questionnaire data concerning clinical diagnosis is disputable. The symptoms of asthma and chronic obstructive pulmonary disease (COPD) are to a great extent similar, especially among older age groups; thus, to distinguish between chronic bronchitis and asthma can be difficult. Those who were treated with 
antiasthma drugs had, however, received their prescriptions from doctors because of respiratory symptoms and had probably been diagnosed by their doctors. The age distribution for the different disorders (table 3 ) and smoking status are what could be expected. We therefore assume that the diagnoses reported by the drug users are comparable to other epidemiological data, e.g. on the prevalence of asthma when the population is asked: "Have you ever had asthma?"

It is interesting that two thirds of the users claimed to have had asthma, and asthma was the most common diagnosis in all age groups. COPD hardly existed among children, and asthma is usually underdiagnosed among children [9]. Those cases classed as chronic bronchitis and emphysema among children $(6 \%)$ probably belonged to the asthma group. Accordingly, $73 \%$ of the antiasthma drug use was because of asthma, $23 \%$ because of COPD, and $3 \%$ for cough; $1 \%$ of the users were unaware of their diagnosis. Antiasthma drugs are, therefore, to some extent used for respiratory disorders other than asthma, especially for emphysema and chronic bronchitis. Such use is, of course, justifiable, at least in most cases, and is in accordance with therapeutic traditions in Europe [10]. The usefulness of inhaled corticosteroids in emphysema and chronic bronchitis has, however, not been proven as clearly as it has for asthma [11-13]. According to our results, antiasthma drugs are only used on a limited scale for symptoms such as cough (3\%), when there is no specific diagnosis.

Our results indicate that the majority of Icelandic asthma patients were treated in accordance with international guidelines $[1,2]$, as $62 \%$ had inhaled corticosteroids, whereas very few had beta ${ }_{2}$-agonists and theophylline without inhaled steroids (5\%), and only $2 \%$ had theophylline as a monotherapy. These patients should, according to international guidelines, be treated with inhaled steroids; this was also likely to be the case for the majority of these 57 who had received systemic corticosteroids during the preceding 12 months, but were not being treated with inhaled steroids at the time of the study. We also believe that some of the patients treated only with beta 2 -agonists $(31 \%$ of the total) would have benefited from inhaled steroids. This is in accordance with a recent Finnish study, in which even patients with mild asthma had a better long-term prognosis when using inhaled corticosteroids [14]. However, a higher proportion of Icelandic asthma patients seems to be treated with inhaled steroids, compared to other areas of the world $[4,15]$. In a recent Swedish survey, only $43 \%$ of asthmatic patients receiving beta ${ }_{2}$-agonists were also treated with inhaled steroids, but in Iceland the proportion was $67 \%$ [15]. This is in accordance with the increase in sales of inhaled steroids in Iceland from 6.8 DDDs per 1,000 inhabitants in 1989 to 13.9 DDDs per 1,000 inhabitants in 1993. The proper care of asthma patients has been shown to be economical, on a national basis, at least in Sweden, where one Swedish crown spent on inhaled steroids resulted in two crowns saved in hospital costs [16]. In the USA, the use of inhaled steroids is much lower than in the present study [4].

The daily doses of inhaled steroids in Iceland were quite high, and one might wonder whether they were in some cases too high. Long-term use of high doses $\left(\geq 1,200 \mu \mathrm{g} \cdot \mathrm{day}^{-1}\right)$ leads to systemic side-effects (effect on bone growth in children, demineralization, etc.). International guidelines also emphasize that maintenance doses should be as low as possible [1, 2]. The highest doses were prescribed to children in Iceland, though the usual duration of treatment was probably shorter.

Acknowledgements: The authors wish to thank all of the pharmacists and their personnel for assistance in collecting data.

\section{References}

1. British Thoracic Society, British Paediatric Association, Royal College of Physicians of London, The Kings Fund Centre, The National Asthma Campaign, et al. Guidelines on the management of asthma. Thorax 1993; 48: S1-S24.

2. National Asthma Education Program. Executive summary: guidelines for the diagnosis and management of asthma. Bethesda, MD, National Institutes of Health, 1991; NIH publication No. 91-3042A.

3. Boëthius G, Blöndal T, Forsén K-O, Johansen B, Laursen LC. Sales of antiasthmatic drugs in the Nordic countries, 1979-1989. Eur Respir Rev 1991; 5: 321-332.

4. Sly RM. Changing asthma mortality and sales of inhaled bronchodilators and antiasthmatic drugs. Ann Allergy 1994; 73: 439-443.

5. WHO Collaborating Centre for Drug Statistics Methodology and Nordic Council of Medicines. Guidelines for ATC classification. Oslo, 1990.

6. Burney PGJ, Luczynska CM, Chinn S, Jarvis D. The European Community Respiratory Health Survey. Eur Respir J 1994; 7: 954-960.

7. Thors H, Sigurdsson H, Oddsson E, Pjódleifsson B. Survey of prescriptions for peptic ulcer drugs. Scand $J$ Gastroenterol 1994; 29: 988-994.

8. Crompton GK. Problems patients have using pressurized aerosol inhalers. Eur J Respir Dis 1982; 63 (Suppl. 119): 101-104.

9. Speight ANP, Lee DA, Hey EN. Underdiagnosis and undertreatment of asthma in childhood. Br Med J 1988; 268: 1253-1256.

10. Siafakas NM, Vermeire P, Pride NB, et al. Optimal assessment and management of chronic obstructive pulmonary disease (COPD): ERS Consensus Statement. Eur Respir J 1995; 8: 1398-1420.

11. Wedzicha JA. Inhaled corticosteroids in COPD: awaiting controlled trials. Thorax 1993; 48: 305-307.

12. Weir DC, Burge PS. Effects of high doses of inhaled beclomethasone dipropionate, $750 \mu \mathrm{g}$ and $1,500 \mu \mathrm{g}$ twice daily, and $40 \mathrm{mg}$ per day oral prednisolone on lung function, symptoms, and bronchial hyperresponsiveness in patients with nonasthmatic chronic airflow obstruction. Thorax 1993; 48: 309-316.

13. Kerstjens HAM, Brand PLP, Hughes MD, et al. A comparison of bronchodilator therapy with or without inhaled corticosteroid therapy for obstructive airways disease. N Engl J Med 1992; 327: 1413-1419.

14. Haahtela T, Järvinen M, Kava T, et al. Comparison of beta $_{2}$-agonist, terbutaline, with an inhaled corticosteroid, budesonide, in newly detected asthma. $N$ Engl J Med 1991; 325: 388-392.

15. Larsson L, Boëthius G, Uddenfeldt M. Differences in utilisation of asthma drugs between two neighbouring Swedish provinces: relation to prevalence of obstructive airway disease. Thorax 1994; 49: 41-49.

16. Gerdtham U-G, Hertzman P, Jönsson B, Boman G. Impact of inhaled corticosteroids on acute asthma hospitalization in Sweden. 1978-1991. Med Care 1996; 34: 1188-1198. 